\title{
Die Keuring van Eerstejaarstudente in die Departement Spraakheelkunde en Oudiologie (Universiteit van Pretoria)
}

\author{
Isabel C Uys DPhil (Pret) \\ Erna Alant MA(Log) (Pret) \\ Departement Spraakheelkunde en Oudiologie \\ Universiteit van Pretoria
}

\begin{abstract}
OPSOMMING
Die artikel handel oor die keuring van logopedika-studente aan die Universiteit van Pretoria en beskryf die kompleksiteit van hierdie prosedure. Die huidige benadering poog om studente te selekteer wat die kursus suksesvol kan voltooi, met die aanname dat 'n toegewyde student wel deur die regte supervisie gelei kan word tot ' $n$ volwaardige terapeut. Gerekenariseerde data illustreer sekere verhande tussen studenteprestasies in die finale jaar en inisiële keuringtellings. Hierdie inligting word geïnterpreteer in terme van die tekortkominge sowel as sterk punte van so 'n benadering.
\end{abstract}

\section{ABSTRACT}

This article deals with the selection of speech therapy students at the University of Pretoria and describes the complexity of this process. The present approach attempts to select students that have potential to successfully complete the course, with the assumption that with appropriate supervision, these students can be guided to become competent speech therapists. Computerized data illustrates certain correlations between students' achievements in the final year and initial selection scores. This information is interpreted in terms of the short-comings as well as strengths of this approach.

Meeste van die gevestigde professionele kursusse word op die een of die ander tyd gekonfronteer met 'n probleemtoestand wat keuring van voornemende' studente noodsaak.

By die Universiteit van Pretoria, soos seker ook by ander universiteite die geval is, is die uitsoek van die beste studente vir een bepaalde kursus ten koste van ander kursusse 'n vreemde gedagte. In die geval van die B' Log-kursus het verskeie faktore daartoe aanleiding gegee dat keuring corweeg moes word, $\mathrm{nl}$.

- studentetalle het vanaf 1971-1976 aansienlik toegeneem, te wete 'n toename van $109,1 \%$ by eerstejaarstudente en $92,2 \%$ by alle jaargroepe tesame in die departement.

- Die fisiese opleidingsfasiliteite kon nie in der mate uitgebrei en aangepas word om al die studente, veral met betrekking tot praktiese opleidingsgeriewe, sinvol te akkommodeer nie.

- 'n Bykomende faktor waarvan kennis geneem moes word, is die wyse waarop natuurlike seleksie wel gemanifesteer het. In die periode vanaf 1971-1975 het gemiddeld slegs 50\% van die studente gekwalifiseer. Met die toename in studentetalle is daar ook ' $n$ beduidende afname in die slaagsyfer bemerk.

In 'n poging om die vereiste akademiese en praktiese standaarde te handhaaf, is dus besluit om 'n ondersoek te loods na die wenslikheid van keuring. 'n Vasgestelde inname sou kwaliteitskontrole verseker en die natuurlike seleksie (staking, druip- syfer, ens.) laat afneem. Kandidate met die grootste potensïle kans op akademiese sukses sou toegelaat word tot die kursus. Hierdie oorwegings geld dan ook by verskeie kursusse ter plaatse en oorsee. (Hilson en McKendrick 1978; Furler-Kools 1981)

\section{BESKRYWING VAN DIE KEURINGSPROSEDURES}

Die Afdeling Universiteitsonderwysbeplanning van die Studentediensburo in samewerking met die Departement Spraakheelkunde en Oudiologie het 'n deeglike veldverkenning gedoen met die oog op die samestelling van 'n bevredigende keuringsmeganisme.

Daar bestaan werklik min navorsingsgegewens oor keuring. Uit alle beskikbare studies blyk dit egter dat keurders met een grondliggende probleem te doen $\mathrm{kry}, \mathrm{ml}$. word studente gekeur met die oog op die suksesvolle voltooiing van hulle opleiding, of met die oog op sukses in die toekomstige praktyk? (FurlerKools 1981; Hilson en McKendrich 1978).

Anders gestel: moet goeie studente of goeie terapeute geselekteer word? Hierdie dilemma word gekompliseer deur die gebrek aan wetenskaplike bewyse oor die verband tussen opleidingsondervinding en praktykvereistes (Malan 1979). Dit lyk asof opvoedkundige en praktykdoelwitte selfs in sekere opsig- 
te van mekaar kan verskil. Hilson en McKendrick (1978) brei op hierdie verskille uit waar dit betrekking het op die maatskaplike werk. Indien die potensieël-suksesvolle student gesoek word sal daar bewyse van akademiese vermoëns en intellektuele kapasiteit moet wees. Daarteenoor, sal die potensieëlsuksesvolie maatskaplike werker sekere persoonlikheidseienskappe moet openbaar, bv. volwassenheid en emosionele stabiliteit. Hierdie bevindings is eweneens van toepassing op die spraakterapeut-oudioloog.

Matriekresultate (akademiese en intellektuele vermoëns) blyk nog steeds die beste indikator van sukses op die tersiêre onderwysvlak te wees. Dit is 'n sterk motivering vir keuring op grond van akademiese prestasie. Ongelukkig is dit so dat die mens nie voorspelbaar is nie. Geen keuringstelsel kan ooit waterdig wees nie. Soos in die geval van maatskaplike werk (Hilson en McKendrick 1978) kan mens alleenlik hoop dat die student na 'n versigtig-beplande opleiding, ook in die praktyk sukses sal bereik. Dit is juis hierdie aanname wat die keuring van verskeie kursusse (Malan 1979; Hilson en McKendrick 1978 en Staf van die Opleiding Logopedie, Hoensbroek 1981) rig.

Uit die voorafgaande blyk dit dat verskeie vrae moes beantwoord word voordat 'n sinvolle keuringsprosedure opgestel kon word:

- Watter eienskappe word gesoek in die voornemende B Logstudent?

- Watter prosedure sal hierdie eienskappe uitlig?

- Wanneer moet keuring plaasvind?

- Deur wie moet die keuring hanteer word?

Aan die hand van beginselbesluite in die beantwoording van die bogenoemde vrae, het die belang van die volgende na vore gekom, nl. akademiese en intellektuele vermoëns, spesifieke persoonlikheidseienskappe (aanleg, menslike dienslewering, motivering, ens.) asook normale spraak, stem en gehoor. Met die oog hierop is op die volgende keuringsprosedures besluit:

\section{AANTAL STUDENTE}

Met inagneming van beskikbare opleidingsfasiliteite is besluit op 'n maksimum van 25 studente per jaar.

\section{EERSTE KEURING}

Die eerste keuring vind teen die einde van die jaar plaas en word gegrond op die kandidaat se prestasie in die rekordeksamen, omdat die eindeksamenpunt nog nie beskikbaar is nie. Hiervolgens word 50 kandidate tot die finale keuring toegelaat.

\section{FINALE KEURING}

Die finale keuring vind gedurende Januarie plaas en in hierdie geval word gebruik gemaak van akademiese prestasie, groeptoetse, 'n persoonlike onderhoud, sowel as 'n evaluasie van die kandidaat se spraak- en gehoorvermoëns.

\section{Akademiese prestasie}

Daar is in beginsel besluit om dié studente wat die grootste kans op sukses in die kursus het, te selekteer. Die finale keursyfer vir akademiese prestasie (met 'n gewig van 50\%) word bereken van die gemiddelde matrikulasie-eindeksamenpunt plus kredietpunte (vir vakke op die hoër graad geslaag, asook enige toepaslike universiteits- en ander kursusse), minus strafpunte (vir universiteits- en ander kursusse wat gedruip is).

\section{Aanleg- en ander toetse}

Omdat daar besluit is dat sekere eienskappe 'n voorvereiste is van suksesvolle voltooiing van die B Log-kursus, is besluit om die volgende groeptoetse af te neem. Al die toetse saam dra 'n gewig van $30 \%$ by tot die totale keursyfer.

\section{Nuwe Suid-Afrikaanse Groeptoets (RGN 1965)}

Die volle skaal van 6 subtoetse (3 verbaal en 3 nie-verbaal) word toegepas om ' $n$ beeld van die kandidaat se algemene intellektuele vermoëns te verkry. Die totale roupunt word met die oog op 'n keurpunt uit 10 verwerk volgens riglyne soos neergelê deur die studentediensburo (U P).

\section{Senior aanlegtoets (RGN 1975)}

Die noodsaaklikheid om sekere eienskappe by voornemende studente te identifiseer word deur verskillende opleidingsinstansies beklemtoon. (Furler-Kools 1981; Staf van die Opleiding Logopedie, Hoensbroek 1981). Aanleg verwys in hierdie toets na spesifieke verstandelike vermoëns wat die persoon in staat stel om sekere vaardighede en bekwaamhede te ontwikkel. Hierdie toets dek 'n baie wye veld en alleenlik drie items is toepaslik gereken by die keuring van B Log-studente, nl. verbale begrip, woordbou en geheue (paragraaf). Hierdie items is aanduidend van die kandidaat se algemene peil van kognitiewe funksionering, redeneringsvermoë, assosiasievlotheid en geheue. Ook hierdie roupunte word volgens 'n tabel tot 'n keurpunt verwerk.

\section{Sestienfaktor-persoonlikheidsvraelys \\ (Cattel, Eber en Tatsoeka 1970)}

Hierdie baie omvattende toets meet sestien afsonderlike persoonlikheidsdimensies waarvolgens uitsprake in verband met verwagte prestasie, beroepsgerigtheid, leierskapeienskappe en selfs moontlike neurotiese neigings gemaak kan word. Vir die doel van die keuring is slegs vyf van die faktore as toepaslik beskou, nl. intelligensie, emosionele rypheid, pligsgetrouheid, skuldgeneigdheid en gespannendheid (d,i. faktore B, D, G, O en Q4).

Ook hierdie roupunte word tot 'n keurpunt verwerk.

Die resultate van hierdie drie toetse gesamentlik stel die keurkomitee in staat om te verseker dat die kandidaat die regte kursus kies, omdat spesifieke vermoëns, algemene kognitiewe vermoëns en persoonlikheidseienskappe ondersoek word. Hierdie gesamentlike punt dra dan die gewig van $30 \%$ by tot die finale keursyfer.

\section{Persoonlike onderhoud}

Die persoonlike onderhoud dra álleenlik 'n gewig van $20 \%$ by tot die finale keursyfer. Die feit dat die onderhoudsvoer- 
ders opgeleide personeel met ervaring is, lei nie noodwendig tot intra- en interbeoordelaar betroubaarheid nie. Daarby duur elke onderhoud ongeveer 10-15 minute, wat 'n baie kort tyd is om aspekte soos gemotiveerdheid en belangstelling, kommunikasie- en taaluitdrukkingsvermoë, tweetaligheid en mensgerigte dienslewering te evalueer.

'n Ander aspek wat egter in 'n persoonlike kontaksituasie hanteer word, is die onderşak van spraak- en gehoorvermoëns. Indien enige sodanige belemmerings die kandidaat se prestasie tydens die opleiding nadelig sal beïnvloed, word die kandidaat afgekeur, afgesien van enige ander keursyfers.

Hierdie keuringsprosedure word vanaf 1977 gevolg. Die eerste gekeurde studente het dus in 1980 gekwalifiseer en daar is besluit dat opvolgingsnavorsing 'n aanvang kan neem, hoewel die steekproef nog relatief klein is. Die belang van langtermynnavorsing, asook korrelasies tussen prestasie op keuring en sukses in die praktyk word besef. Huidiglik is dit egter alleenlik moontlik om navorsing en evaluasie van die keuringsprosedures te rig op finalejaarstudente se prestasie.

\section{EVALUASIE}

\section{METODE VAN EVALUASIE}

Die keuringsprosedure is geëvalueer aan die hand van twee aspekte:

i Vergelyking van die slaagsyfer by kwalifikasie van spraakterapeute vyf jaar voor keuring ingestel is, en drie jaar nadat keuring ingestel is. Hoewel keuring nie hoofsaaklik ingestel word om die slaagsy fer by kwalifikasie te verhoog nie, kan die gegewens moontlik ook 'n aanduiding gee van die algemene toewyding van die studente aan hul studies.

ii Assosiasies van keuringsyfers en prestasiesyfers (akademies sowel as prakties) van finalejaar-(kwalifiserende) spraakterapiestudente. Ideaal gesproke sou die evaluasie van 'n keuringsprosedure slegs kon geskied deur middel van die yérgelyking van gekeurde en ongekeurde studente in dieselfde beroep. Aangesien laasgenoemde nie in die situasie prakties uitvoerbaar is nie, soul 'n mens die gekeurde studente se vordering in die spraakterapiekursus noukeurig kon dophou en telkens prestasic van die studente vergelyk met die aanvanklike keuringstellings. Hilson et al (1978) het byvoorbeeld keuringstellings vergelyk met die prestasietellings van maatskaplike werkstudente aan die einde van hul eerste jaar. Aangesien die eerste jaar in die spraakterapiekursus egter baie inleidend van aard is (bv. baie beperkte prakties word gedoen), is gevoel dat die waarde van keuring by spraakterapie meer sigbaar kan word wanneer die keuringstellings vergelyk word met die kwalifiserende prestasies. Dit is dan ook teen hierdie agtergrond dat daar besluit is om gebruik te maak van die finalejaar-prestasietellings en dié te vergelyk met keuringstellings.

\section{Steekproef}

Alle gekeurde studente (tussen 1977 en 1979) wat gekwalifiseer het (tussen 1981 en 1983) is by die studie ingesluit (sien Tabel 1).
Tabel 1 Steekproefbeskrywing

\begin{tabular}{|c|c|c|c|}
\hline Jaar & Herhalers & $\begin{array}{c}\text { Nuwe } \\
\text { Kandidate }\end{array}$ & $\begin{array}{c}\text { Gekwalifiseerde } \\
\text { terapeute }\end{array}$ \\
\hline 1977 & - & 25 & 18 \\
1978 & 2 & 23 & 15 \\
I979 & 2 & 23 & 18 \\
\hline Totaal & 4 & 71 & 51 \\
\hline
\end{tabular}

'n Totaal van 51 studente is dus by die studie betrek.

\section{Dataverwerking}

Die data is gerekenariseer waarna beskrywende statistiek sowel as verskeie korrelasies tussen veranderlikes bereken is. 'n Inferensie insake die korrelasiekoëffisiënt het verskeie liniêre verbande tussen sekere veranderlikes bevestig. Volgens hierdie metode word 'n p-waarde kleiner as 0,05 geïnterpreteer as betekenisvol (Steyn, Smit, Du Toit 1984).

\section{RESULTATE}

VERGELYKING VAN SLAAGSYFER (AAN DIE EINDE VAN DIE FINALE JAAR) GEDURENDE VYF JAAR VOOR KEURING (SIEN TABEL 2) EN DIE SLAAGSYFER GEDURENDE DRIE JAAR NA KEURING INGESTEL IS (SIEN TABEL 3)

\section{Tabel 2 Ongekeurde finalejaarstudentesyfers}

\begin{tabular}{|c|c|c|c|}
\hline \multirow{2}{*}{ Jaar } & \multirow{2}{*}{$\begin{array}{c}\text { Aantal } \\
\text { eerste jaars }\end{array}$} & $\begin{array}{c}\text { Aantal } \\
\text { gekwalifiseer }\end{array}$ & $\begin{array}{c}\text { Persentasie } \\
\text { Pekwalifiseer } \\
\text { gekwe }\end{array}$ \\
\cline { 3 - 4 } & 33 & 11 & 33 \\
1971 & 31 & 27 & 87 \\
1972 & 39 & 21 & 54 \\
1973 & 55 & 22 & 40 \\
1974 & 53 & 19 & 36 \\
1975 & 211 & 100 & 50 \\
\cline { 3 - 3 } Totaal & &
\end{tabular}

Tabel 3 Gekeurde finalejaarstudentesyfers

\begin{tabular}{|c|c|c|c|}
\cline { 3 - 3 } Jaar & $\begin{array}{c}\text { Aantal } \\
\text { eerste jaars }\end{array}$ & $\begin{array}{c}\text { Auntal } \\
\text { gekwalifiseer }\end{array}$ & $\begin{array}{c}\text { Persentasie } \\
\text { gekwalifiseer }\end{array}$ \\
\hline 1977 & 25 & 18 & 72 \\
1978 & 25 & 15 & 60 \\
1979 & 25 & 18 & 72 \\
\hline Totaal & 75 & 51 & 68 \\
\hline
\end{tabular}

Uit bogenoemde tabelle blyk dit dat die gemiddelde slaagsyfer by kwalifikasie toegeneem het met $18 \%$ sedert keuring ingestel is. 
ASSOSIASIES VIR KEURINGSYFERS EN DIE PRESTASIE BY FINALEJAARSTUDENTE

Korrelasiematriks vir assosiasies van keuringsyfers en die prestasie by finalejaarstudente

\begin{tabular}{|c|c|c|c|c|c|}
\hline & & Aanlegtoetse & Onderhoud & $\begin{array}{l}\text { Matriek- } \\
\text { prestasie }\end{array}$ & $\begin{array}{c}\text { Finale } \\
\text { keuringspunt }\end{array}$ \\
\hline & Praktiese jaarpunt & $\begin{array}{r}-0.20881 \\
0.1414\end{array}$ & $\begin{array}{r}0.25940 \\
0.0660\end{array}$ & $\begin{array}{r}0.25077 \\
0.0759\end{array}$ & $\begin{array}{r}0.09699 \\
0.4984\end{array}$ \\
\hline & Teoriejaarpunt & $\begin{array}{l}0.01871 \\
0.8963\end{array}$ & $\begin{array}{r}0.15535 \\
0.2763\end{array}$ & $\begin{array}{r}0.57103 \\
0.0001\end{array}$ & $\begin{array}{r}0.42570 \\
0.0018\end{array}$ \\
\hline \multirow[t]{5}{*}{ Spraak heelkunde } & Totale jaarpunt & $\begin{array}{r}-0.11859 \\
0.4112\end{array}$ & $\begin{array}{r}0.25191 \\
0.0745\end{array}$ & $\begin{array}{r}0.48316 \\
0.0003\end{array}$ & $\begin{array}{r}0.30761 \\
0.0281\end{array}$ \\
\hline & Eksamenpunt & $\begin{array}{r}0.02520 \\
0.8607\end{array}$ & $\begin{array}{r}0.23497 \\
0.0970\end{array}$ & $\begin{array}{r}0.34233 \\
0.0139\end{array}$ & $\begin{array}{r}0.30932 \\
0.0272\end{array}$ \\
\hline & Finale punt & $\begin{array}{r}-0.02649 \\
0.8536\end{array}$ & $\begin{array}{r}0.25633 \\
0.0694\end{array}$ & $\begin{array}{r}0.42208 \\
0.0020\end{array}$ & $\begin{array}{r}0.32976 \\
0.0181\end{array}$ \\
\hline & Praktiese jaarpunt & $\begin{array}{r}-0.35374 \\
0.0109\end{array}$ & $\begin{array}{l}0.09118 \\
0.5246\end{array}$ & $\begin{array}{r}0.19728 \\
0.1652\end{array}$ & $\begin{array}{r}-0.07846 \\
0.5842\end{array}$ \\
\hline & Teoriejaarpunt & $\begin{array}{r}-0.20149 \\
0.1562\end{array}$ & $\begin{array}{r}0.06024 \\
0.6745\end{array}$ & $\begin{array}{r}0.37900 \\
0.0061\end{array}$ & $\begin{array}{l}0.15814 \\
0.2677\end{array}$ \\
\hline \multirow[t]{5}{*}{ Oudiologie } & Totale jaarpunt & $\begin{array}{r}-0.31969 \\
0.0222\end{array}$ & $\begin{array}{r}0.09862 \\
0.4911\end{array}$ & $\begin{array}{r}0.34480 \\
0.0132\end{array}$ & $\begin{array}{r}0.05938 \\
0.6790\end{array}$ \\
\hline & Eksamenpunt & $\begin{array}{r}-0.04961 \\
0.7296\end{array}$ & $\begin{array}{r}0.20213 \\
0.1549\end{array}$ & $\begin{array}{r}0.48404 \\
0.0003\end{array}$ & $\begin{array}{r}0.35022 \\
0.0118\end{array}$ \\
\hline & Finale punt & $\begin{array}{r}-0.16401 \\
0.2501\end{array}$ & $\begin{array}{r}0.16847 \\
0.2373\end{array}$ & $\begin{array}{r}0.50310 \\
0.0002\end{array}$ & $\begin{array}{r}0.28122 \\
0.0456\end{array}$ \\
\hline & Praktiese jaarpunt & $\begin{array}{r}-0.31179 \\
0.0259\end{array}$ & $\begin{array}{r}0.20067 \\
0.1580\end{array}$ & $\begin{array}{r}0.25249 \\
0.0739\end{array}$ & $\begin{array}{r}0.01471 \\
0.9184\end{array}$ \\
\hline & Teoriejaarpunt & $\begin{array}{r}-0.10269 \\
0.4733\end{array}$ & $\begin{array}{l}0.12145 \\
0.3959\end{array}$ & $\begin{array}{r}0.53497 \\
0.0001\end{array}$ & $\begin{array}{r}0.22890 \\
0.0184\end{array}$ \\
\hline \multirow[t]{3}{*}{$\begin{array}{l}\text { Kombineer Spraakheelkunde } \\
\text { en Oudiologie }\end{array}$} & Totale jaarpunt & $\begin{array}{r}-0.23606 \\
0.0954\end{array}$ & $\begin{array}{r}0.18977 \\
0.1823\end{array}$ & $\begin{array}{r}0.44786 \\
0.0010\end{array}$ & $\begin{array}{r}0.19883 \\
0.1619\end{array}$ \\
\hline & Eksamenpunt & $\begin{array}{r}-0.01191 \\
0.9339\end{array}$ & $\begin{array}{r}0.24445 \\
0.0838\end{array}$ & $\begin{array}{r}0.45753 \\
0.0007\end{array}$ & $\begin{array}{r}0.36681 \\
0.0081\end{array}$ \\
\hline & Finale punt & $\begin{array}{r}-0.09709 \\
0.4979\end{array}$ & $\begin{array}{r}0.22793 \\
0.1077\end{array}$ & $\begin{array}{r}0.48850 \\
0.0003\end{array}$ & $\begin{array}{r}0.32556 \\
0.0197\end{array}$ \\
\hline
\end{tabular}

Die volgende gegewens (sien Tabel 5 en 6) kan uit tabel 4 onttrek word ter verduideliking van betrokke assosiasies.

Tabel 5 Betekenisvolle assosiasies tussen teoretiese en keuringsyfers

\begin{tabular}{|c|c|c|c|}
\hline $\begin{array}{l}\text { Keurings- } \\
\text { prosedure }\end{array}$ & $\begin{array}{c}\text { Spraak- } \\
\text { heelkunde }\end{array}$ & Oudiologie & Gekombineerd \\
\hline Aanlegtoetse & - & - & - \\
\hline Onderhoud & - & - & - \\
\hline $\begin{array}{l}\text { Matriek- } \\
\text { prestasie }\end{array}$ & $0,0001^{*}$ & $0,0160^{*}$ & $0,0001^{*}$ \\
\hline $\begin{array}{l}\text { Finale } \\
\text { keuringspunt }\end{array}$ & $0,0042^{*}$ & - & $0,0559^{*}$ \\
\hline
\end{tabular}

Dit blyk duidelik uit voorafgaande dat matriekresultate die enigste veranderlike is wat ' $n$ betekenisvolle verband vertoon met die teoretiese punte gedurende die jaar. Dieselfde neiging is ook waarneembaar wanneer die eksamenpunte inaggeneem word in Tabel 4.
Tabel 6 Betekenisvolle assosiasies tussen praktiese jaarpunt en keuringsyfers

\begin{tabular}{|c|c|c|c|}
\hline $\begin{array}{c}\text { Keurings- } \\
\text { prosedure }\end{array}$ & $\begin{array}{c}\text { Spraak- } \\
\text { heelkunde }\end{array}$ & Oudiologie & Gekombineerd \\
\hline $\begin{array}{c}\text { Aanlegtoetse } \\
\text { Onderhoud } \\
\text { Matriek- } \\
\text { prestasie }\end{array}$ & - & $-0.0308^{*}$ & $-0,0830^{*}$ \\
Finale \\
keuringspunt
\end{tabular}

Uit die bogenoemde blyk dit dat 'n negatiewe betekenisvolle verband bestaan tussen resultate van die aanlegtoetse en oudiologie prakties, asook die gekombineerde praktiese punt. Geen verdere betekenisvolle assosiasies is duidelik nie. 
BESKRYWENDE STATISTIEK MET BETREKKING TOT DIE ONDERSKEIE KEURINGSASPEKTE

Tabel 7 Gemiddelde telling en standaard afwyking van keuringsaspekte

\begin{tabular}{|l|c|c|}
\cline { 1 - 1 } & Gemiddeld & $\begin{array}{c}\text { Standaard } \\
\text { afwyking }\end{array}$ \\
\cline { 1 - 1 } Aanlegtoetse & 20.54901961 & 3.39596069 \\
Onderhoud & 14.78235294 & 1.79105621 \\
Matriekprestasie & 37.12941176 & 3.88197342 \\
- Finale keuringspunt & 72.29019608 & 6.12929165 \\
\hline
\end{tabular}

Uit voorafgaande tabel blyk dit dat die 'onderhoud' in die prosedure die kleinste standaard afwyking toon, met ander woorde, die kleinste variasie rondom die gemiddelde. Laasgenoemde is interessant aangesien dit impliseer dat hierdie groep meer homogeen was wat betref hulle tellings op hierdie keuringsaspek.

\section{BESPREKING}

Matriekprestasie was die mees konstante indikator van teoretiese prestasie van die studente in oudiologie sowel as spraakheelkunde. Hierdie bevinding is ook gestaaf in Hilson et al. (1978) se studie op maatskaplike werkstudente.

Wat egter effe verontrustend is, is die neiging wat betref die korrelasie tussen die praktiese punte en keuringspunte. Die enigste betekenisvolle verband gevind in hierdie korrelasie is tussen aanlegtoetse en oudiologie-prakties, en hierdie verband is 'n negatiewe verband.

Hoewel so 'n bevinding oënskynlik verbasend kon wees, kan dit moontlik verklaar word aan die hand van die betrokke toetse wat ingesluit is onder die kategorie 'aanlegtoetse'.

Die aanlegtoetspunt word verkry deur die som van gegewens op drie toetse wat elk op ' $n$ tienpuntskaal beoordeel word. Hierdie drie toetse gekombineer dra by tot $30 \%$ van die keuringstelling.

Die toetse is die volgende: Senior aanlegtoets (SAT), Nuwe Suid-Afrikaanse Groepstoets (NSAG), Persoonlikheidsvraelys (16-PF - slegs vyf van die sestien faktore word inaggeneem by keuring: intelligensie, pligșgetrouheid, skuldgeneigdheid, gespannendheid en emosionele rypheid). Wanneer hierdie toetse van nader beskou word blyk dit dat daar 'n baie groot klem is op die meting van intellektuele vermoëns van kandidate. Die SAT sowel as die NSAGT meet kognitiewe funksionering, spesifiek en algemeen, met ander woorde, ten minste $20 \%$ van die aanlegtoetspunt word verteenwoordig deur ' $n$ kognitiewe metingspunt.

In hierdie lig gesien, sou 'n mens nie noodwendig 'n positiewe korrelasie verwag tussen praktiese werk en aanlegtoetse nie aangesien daar nie noodwendig 'n noue verband bestaan tussen praktiese vaardigheid en intellektuele of akademiese vermoëns nie (Hilson et al 1978). Terselfdertyd kan die voorafgaande argument nie gesien word as 'n verklaring van 'n betekenisvolle negatiewe verband tussen intellektuele vermoëns (soos hier getoets) en praktiese punte nie. Die grootte van die huidige steekproef kon inderdaad ' $n$ faktor gewees het by hierdie bevinding. Dit sou dus onvanpas wees om hierdie resultate as allesomvattend te beskryf.

Nog 'n interessante waarneming wat gemaak kan word, is die afwesigheid van enige verband tussen die 'onderhoud' tydens keuring en die teoretiese en praktiese punte. Wanneer die standaard afwyking vir die groep se onderhoudtellings beskou word, word dit duidelik dat die gekeurde studente baie dieselfde punte behaal het in die onderhoud. Hieruit kan moontlik die volgende afleidings gemaak word: dat alle kandidate dieselfde eienskappe gehad het met betrekking tot die aspekte gedek in die onderhoud (motivering en belangstelling kommunikasie en taaluitdrukking, mensgerigte dienslewering en algemene ingesteldheid en voorkoms); dat die vier aspekte gedek in die onderhoud te wyd gedefinieer is en derhalwe nie individuele verskille reflekteer nie.

Hilson et al (1978) het wel 'n betekenisvolle verband tussen die onderhoud in seleksie en finale eerstejaarspunte gevind. Mens sou moontlik hierdie verband kon verklaar in terme van die relatiewe kort tyd wat verloop het tussen die keuringstyd (met ander woorde, die begin van die jaar) en die eksamen aan die einde van die jaar. Blootstelling aan die kursus tydens die eerste jaar is inleidend van aard en kan dus nie in werklikheid gesien word as ' $n$ betroubare maatstaf vir die evaluasie van die keuringsprosedure nie. Dit is nie noodwendig te sê dat alle studente wat die eerste jaar slaag die kursus gaan voltooi nie.

Die huidige studie het dus eerder die finalejaarprestasie geneem as maatstaf. Dit impliseer egter dat daar ' $n$ vier jaar verloop is tussen die 'onderhoud' (of enige ander keuringstelling) en die prestasiepunt. Gedurende hierdie tyd word die studente nie alleenlik blootgestel aan die terapeutiese situasie nie, maar vereis die kursus dat studente emosionele groei toon om steeds meer veeleisende pasiënte in die terapiesituasie te kan hanteer. Dit is dus nie heeltemal verrassend wanneer die huidige bevindings toon dat daar geen betekenisvolle verband bestaan tussen die aanvanklike onderhoudspunte en finalejaarprestasie nie. Laasgenoemde kan gemotiveer word deurdat die onderhoud soos gedefinieer in ' $n$ vorige paragraaf nie potensiële emosionele groei uitlig nie, maar wel klem lê op die student se belangstelling en ingesteldheid tydens die onderhoud. Die fokus in keuring is dus op die seleksie van studente wat die opleiding suksesvol kan voltooi, eerder as die keuring van studente in terme van hul potensiaal vir toekomstige praktyk (Hilson et al 1978). Dit is veral duidelik wanneer gekyk word na die keuringsprosedure in terme van kognitiewe funksionering, matriekprestasie, ingesteldheid en belangstelling tydens aansoek.

Die aanname wat hier gemaak word, is dat die gekeurde student gelei kan word om 'n goeie terapeut te word onder bevoegde leiding. Dit impliseer dat die proses van kliniese supervisie tydens opleiding baie sterk benadruk word (Oratio 1977; Lewis 1983).

Soos blyk uit die bespreking, is die konsep van 'keuring' voorwaar kompleks. Dit spruit nie net uit die probleme by die seleksie van faktore wat ingesluit moet word in die keuring nie, maar ook uit die dilemma van wanneer die beste tyd sou wees om die effektiwiteit van die keuringsprosedure te toets, asook die keuse van maatstawwe waaraan keuringseffektiwiteit gemeet kan word - bo en behalwe akademiese prestasie. 
Hoewel daar baie praktiese probleme met die keuring van studente bestaan, is dit egter belangrik dat hierdie aspekte gesien moet word binne die raamwerk van die persentasie van studente wat uiteindelik kwalifiseer. Soos voorheen genoem is daar 'n-duidelike styging in die persentasie van spraakterapeute wat kwalifiseer sedert keuring ingestel is. Hoewel keuring nie gerig is op die verhoging van die släagsyfer in 'n kursus nie, maar eerder die selektering van studente wat die beste bydrae tot die beroep sou kon maak, kan 'n verhoging in slaagsyfer wel 'n maatstaf wees in die meting van betrokkenheid van die student by die kursus. Binne hierdie breë raamwerk sou die proses van keuring wel baie nuttig en relevant wees, hoewel daar noodwendig altyd krities gekyk sal word na die inhoud en wyse van die keuringsproses. Dit is teen hierdie agtergrond dat sekere veranderinge in die bestaande keurings-prosedure gemaak kan word.

Hoewel keuring gerig is op die seleksie van studente wat die spraakterapiekursus suksesvol sal voltooi, is dit nodig vir die keurders om sensitief te wees vir indikatore wat groeipotensiaal by studente kan aandui. Voorbeelde van sulke indikatore is die volgende:

\footnotetext{
- Aanlegtoetse soos hier gedefinieer, sou moontlik aangepas kan word om minder klem te plaas op die kognitiewe vermoëns van die individue, ten einde meer inligting oor die persoonlikheid en belangstellings van die individu te kan insluit.

- Die onderhoudsprosedure kan moontlik gerig word ten einde potensiële groei van die individu te probeer meet. Laasgenoemde sal impliseer dat onderhoudsvoerders moet opgelei word in die kuns van onderhoudsvoering vir hierdie bepaalde doel
}

Dit is ook aan te beveel dat die prestasie op keuringsprosedure gekorreleer word met praktiese vaardighede van terapeute.

Aangesien keuring gerig is om studente te selekteer vir die kursus moet daar gewaak word teen die opskuif van standaarde ten einde 'n 'normale verspreidingskurwe' met betrekking tot punte te verkry, wat noodwendig dui op 'n groepie onsuksesvolle kandidate.
Laastens is die opleiding van personeel in die toesighoudende situasie van kardinale belang om te verseker dat die student die nodige leiding kry om te kan groei tot 'n volwaardige terapeut.

\section{BEDANKINGS}

Graag word erkenning gegee aan die volgende: Afdeling Universiteitsonderwysbeplanning (Studentediensburo, Universiteit van Pretoria) vir waardevolle inligting. Mev F Woodrow (kliniese sielkundige, Department Spraakheelkunde en Oudiologie, UP) vir inligting oor en evaluasie van sielkundige toetse. Mev E.M Louw (Departement Statistiek, UP) vir hulp met statistiese verwerkings.

\section{VERWYSINGS}

Cattell R.B., Eber H.W. en Tatsoeka M.M. Handbook for the 16 Personality Factor Questionnaire. Illinois, Institute for Personality and Ability Testing, 1970.

Furler-Kools S. De toelatingsprocedure. Logopedie en Foniatrie, 1981, 53, 11-13.

Hilson F. en McKendrick B. Selecting Students for Admission to Undergraduate Courses of Social Work Education and Training. Maatskaplike werk/Social Work, 1978, 14, 3, 108-114.

Lewis C. Supervision in the Training of Speech Therapists. Unpublished dissertation submitted to the Department of Speech Pathology and the Witwatersrand, Johannesburg, South Africa, 1983.

Malan S.P.T. Evaluering van die keuringstelsel waarvolgens voornemende kandidate vir die diploma in mondhigiëne vanaf 1974-1978 gekeur is. Ongepubliseerde stuk: Studentediensburo, Universiteit van Pretoria, 1979.

Nuwe Suid-Afrikaanse Groeptoets. Raad vir Geesteswetenskaplike Navorsing, Instituut vir Psigometriese Navorsing, 1965.

Oratio A.R. Supervision in Speech Pathology. Baltimore, University Park Press, 1977.

Senior Aanlegtoets. Raad vir Geesteswetenskaplike Navorsing, Instituut vir Psigometriese Navorsing, 1975.

Staf van de Opleiding Hoensbroek. Opleiding Logopedie, Hoensbroek, 1981, 53, 24-38.

Steyn A.G.W., Smit C.F. en Du Toit S.H.C. Moderne statistiek vir die praktyk. Pretoria, Van Schaik, 1984. 


\section{Danavox Bellome DANAC Rastronics}

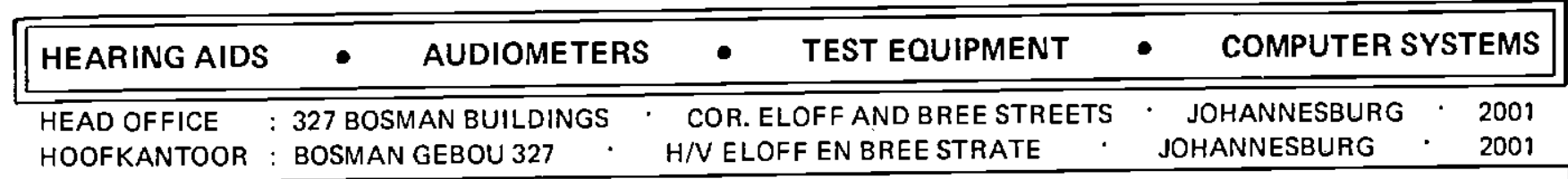

June 1984

Dear Audiologist,

One day soon you will sit behind the panel of a new audiometer with the usual row of buttons and dials.

However, on this occasion you will press just one button and sit back while the audiometer runs through the tests. You will listen to a verbal report on the progress of the test while the audiogram is plotted on a video monitor (the patient will not realise that the test is being controlled by a machine).

Any inconsistencies in the patients responses will be checked and if things get really rough the audiometer will invite you to take over.

This is no gimmick or science fiction toy - it is one of a powerful new breed of instruments which use computer technology to provide consistent test procedures, data evaluation, statistical analysis, graphic storage etc. programmed entirely to your own specifications by Acoustimed these instruments enhance. your facilities for research, educational and clinical procedures.

We provide full software backup and complete custom-designed computer systems.

Please phone me for more details....

sincerely,

D.A. SMITH

MANAGING DIRECTOR

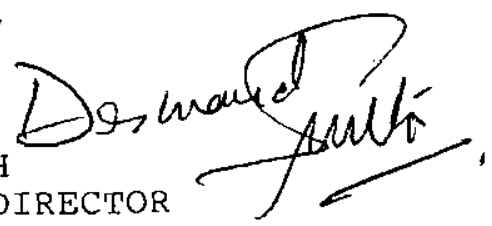

Directors/Direkteure: D.A. Smith (Managing/Besturende), L.M. Smith 